\title{
Participação da População: do Controle sobre os Recursos a uma Produção Estética da Clínica e da Gestão em Saúde
}

\author{
ALCINDO ANTÔNIO FERLA
}

\section{RESUMO}

$\mathrm{O}$ artigo relata parte de trabalho cartográfico realizado pelo autor, que buscou idéias populares e oficiais inovadoras para a clínica e para a pedagogia médica, associando-as a evidências similares coletadas por ocasião da etapa nacional da XII Conferência Nacional de Saúde. Por meio da análise desse material empírico, é possível afirmar que os espaços de participação da população no sistema de saúde vêm produzindo contribuições inovadoras à clínica em saúde e à gestão do sistema de saúde. Essas contribuições atuam no sentido de reconfigurar a clínica e a gestão, interferindo, em grande medida, no próprio sentido do controle social, como habitualmente é referida a diretriz constitucional de participação da população no sistema de saúde. Tal movimento, que fortalece um plano de produção estética desses conceitos, é direcionado de forma similar a um conjunto de processos que marcam, segundo diversos autores, o limite de conceitos que a ciência moderna vem utilizando para produzir conhecimentos. Dessa forma, é possível supor que o que se denomina com alguma freqüência de crise no controle social sobre o sistema de saúde possa ser, na verdade, uma insuficiência de recursos interpretativos para capturar um plano de maior potência da participação da população e de expressão mais atual.

Palavras-chave: Participação da população; clínica em saúde; gestão em saúde; clínica nômade; inovação na saúde. 
A defesa da vida e o compromisso com a vida são valores que nem a mão invisível do mercado, nem a mão pesada do planejamento centralizado e burocrático são capazes de garantir. Valores que, ou vingarão através de empenho, luta, coragem e convicções firmes, ou simplesmente serão suplantados pelo cinismo, pela indiferença, pela cupidez e pelo individualismo mais feroz (Capistrano Filho, 1995, p. 41).

\section{Estética, Conhecimento e Inovação}

Este artigo apresenta parte dos achados da tese de doutoramento (Ferla, 2002) associados a algumas reflexões posteriores, principalmente durante a realização da XII Conferência Nacional de $\mathrm{Saúde}^{2}$. Na tese de doutorado, foi desenvolvida uma cartografia para buscar inovações na formação e na clínica, por meio de uma pesquisa que, entre outros suportes, buscou a produção de idéias no cotidiano do Conselho Estadual de Saúde do Rio Grande do Sul, no período de 1999 a 2001. Os projetos da gestão estadual e de outros temas discutidos nesse fórum permitiram desenvolver algumas reflexões sobre influências da participação da população no desenho da clínica em saúde e da gestão. Na etapa nacional da XII Conferência Nacional de Saúde, evidências capturadas permitem identificar, novamente, tais influências. Estas atuam num plano capaz de produzir o que se poderia chamar de uma estética inovadora, tanto para a clínica quanto para a gestão, e não vêm criando uma nova configuração hegemônica, mas um novo contorno e um certo descentramento em relação à expressão que essas áreas foram tomando, principalmente a partir da modernidade. Evidentemente, a percepção dessa dimensão estética implica a expressão de uma certa sensibilidade diferenciada da expressão que foi tornada "normal" para a produção científica na modernidade e para a produção de conhecimentos nesse contexto 3 .

Compartilhamos da convicção de que produzir conhecimento é uma atividade que se faz com as verdades da inteligência e não com as verdades do pensamento racional explicativo (Ceccim, 1998). Há que se estar, para isso, mergulhado no campo das experimentações e do pensamento exterior que, segundo Guattari (1993), é a instância soberana do saber. Segundo esse autor, os conceitos e as teorias "valem" pela vida que lhe é dada: o conceito teórico "tem menos por função guiar a representação e a ação do que catalisar os universos de referência que configuram um campo pragmático" (Guattari, 1993, 
p. 201). Assim, teoria e prática devem ter relações de transversalidade, revezamentos e ações de rede, conforme nos apresentam os autores que buscam transpor os já reconhecidos limites da racionalidade científica moderna.

Gilles Deleuze, em conversa com Michel Foucault, nos diz que "nenhuma teoria pode se desenvolver sem encontrar uma espécie de muro e é preciso a prática para atravessar o muro" (Foucault, 1989, p. 70). Da mesma forma, Prigogine e Stengers (1997) nos dizem da necessidade de uma nova aliança entre o homem e o universo que este observa, para devolver à ciência seu potencial inovador, sem universais de certeza: não vivemos uma ordem linear e estável, como ainda nos quer convencer a razão moderna, "mas um mundo aberto, cuja atividade produz novidade, cuja evolução é inovação, criação e destruição, nascimento e morte" (Prigogine e Stengers, 1997, p. 125).

Eis a intenção deste artigo: chamar a atenção para uma produção que está apenas tenuamente no plano visível, mas que tensiona e pode renovar conhecimentos e práticas vigentes. Essa vertente de produção de conhecimentos tem grande capacidade de dialogar com uma certa sensação de crise que perpassa diversas análises recentes sobre o chamado "controle social na saúde" $"$.

\section{Uma Cartografia para Permitir a Busca de Inovações}

Há alguns anos buscamos, principalmente em reflexões acadêmicas no campo da Educação e da Saúde Coletiva, ferramentas para fortalecer nosso olhar sobre o campo profissional da medicina - outro olhar (mais sensível) para a clínica em saúde, outras possibilidades epistemológicas, políticas e sociais na pesquisa acadêmica, na formação profissional e na luta política. Um olhar com competência fisiológica para o visível dos sinais e sintomas, mas também capaz de produzir visibilidade às condições subjetivas e experienciais da vida das pessoas.

As possibilidades de qualificação contínua e de ajustamento do trabalho em saúde às forças que desenham mais justiça, mais liberdade e uma democracia mais densa, impregnada de cidadania e solidariedade, são emergências da ação educativa dos profissionais, dos gestores e dos conselheiros de saúde que precisam se tornar visíveis e fortalecidas. 
Buscamos um olhar que permita compor o que denominamos de clínica nômade (Ferla, 2002), isto é, uma clínica que possa abrir mão das representações estanques, que lhe produzem a identidade configurada pela modernidade, para comprometer-se com a qualidade e com a intensidade de vida das pessoas sob atendimento em saúde, reconfigurando-se constantemente. Histórica e socialmente constituída, a clínica foi aprisionada na modernidade no interior do paradigma biomédico. Ao invés dessa identidade, buscamos outras vigências, outros modos de relação mais fortes com o andar da vida - enfim, uma clínica capaz de escutar a vida (Ceccim, 1997) e de produzir atenção à saúde configurada a partir de perspectivas ético-estético-políticas (Rolnik, 1993) e não identitárias ou baseadas exclusivamente em evidências fisiopatológicas impessoais, atemporais e anistóricas. Também buscamos outras configurações para a pedagogia medicalizadora sobre a qual a clínica moderna está assentada e para a gestão da saúde, que precisa desenvolver tecnologias para a potencialização de novas práticas no cotidiano dos serviços.

Algumas produções atuais na periferia dos espaços de participação da população e no cotidiano dos serviços de saúde podem estimular a emergência de uma clínica com capacidade de subordinar as potencialidades do conhecimento médico-científico ao compromisso de afirmação da vida e à ousadia de deixar-se desterritorializar e reconstruir no contato com a produção da vida, mais do que se afirma e se fortifica na territorialização pela doença, pelo domínio técnico e discursivo sobre a morte (biológica) e pela sistemática demarcação corporativa com outras práticas, conhecimentos e racionalidades.

Uma clínica capaz de produzir outros padrões de saúde para as pessoas, já que compartilhamos da convicção de que saúde não é exatamente o oposto e a sedação da doença: "não podemos prescindir da doença", nos diz Nietzsche (2002). Entretanto, segundo o mesmo autor, podemos dar "um tremendo choque na vida através (das) grandes doenças". Dessa perspectiva (e desde a experiência empírica que a humanidade acumula no decorrer da sua existência), é falaciosa a idéia de uma sociedade ou momento histórico sem doenças, como também é falsa a oposição dos conceitos da saúde e da doença. Por isso, é preciso dotar a clínica em saúde da capacidade de suscitar possibilidades múltiplas de vida, de fomentar desejos e paixões para assumirem o controle da vida e de mobilizar a vontade de poder no processo orgânico, que ativa suas forças constitutivas (Nietzsche, 2002). 
Esses são aspectos necessários também no exercício de pensar uma educação para a clínica, que traz em si uma nova ação pedagógica, desreificada de uma transmissão técnica e vertical de conhecimentos para uma transversalização dos conhecimentos. Trata-se de fazer funcionar os saberes daqueles com os quais se trabalha afirmando a vida: essa é a competência educativa necessária aos profissionais que atuam nessa área ${ }^{5}$. É preciso fomentar a expressão de devires e intensidades afetivas de afirmação da vida para vingar mais saúde.

Nosso desejo constante é pensar outras possibilidades de exercício da clínica médica que não exclusivamente aquela talhada pela modernidade, ou seja, uma ordenadora e disciplinarizadora aplicação de conhecimentos científicos biomédicos sobre as pessoas que dela necessitam, criando uma relação de submetimento e de controle da vida. Tampouco interessa a negação de todo o desenvolvimento tecnológico que a medicina moderna produziu, mesmo na sua vertente biomédica, potencialmente qualificador das possibilidades e da expectativa da vida humana. Não se trata de fixar a clínica médica nos aspectos marginalizados pela modernidade. A vivência trágica da doença, permitindo a reinvenção dos modos de andar a vida e de interagir em sociedade, não implica resignar-se dramaticamente frente à dor física, ao dano biológico e, menos ainda, à morte prematura ${ }^{6}$. É preciso buscar padrões móveis (ou seja, um território ampliado), outra forma de produção de conhecimentos não alicerçada na doença e uma reconfiguração para essa clínica, a partir das forças de vida e não das idéias de sobrevivência e oposição à morte biológica. Uma recriação permanente (nomadismo), suficiente para que incorpore padrões crescentes de compromisso com a vida, múltipla e sempre renovada, tal como ela pode ser.

Uma clínica inovadora no sentido que dá Boaventura Santos (Santos, 1997) à inovação: produção de tensões, rupturas e transição do paradigma biomédico vigente - que já se mostrou insuficiente e, em muitos aspectos, inadequado -, com reconfiguração de saberes e poderes e expressão de subjetividades. Igualmente, de novos modos de viver em sociedade, capacidade imbricada no conceito de saúde registrado constitucionalmente. Esse e outros documentos que criam o atual formato jurídico do sistema nacional de saúde colocam um campo de ação e percepção do setor muito mais aberto à experiência e à participação da sociedade do que o fixado em discursos teóricos, científicos ou programáticos. No entendimento que temos do processo de 
reformas do setor saúde desde as últimas três décadas do século passado e na leitura das demandas criadas pela configuração atual do sistema nacional de saúde, as mudanças na clínica em saúde são fortemente demandadas e apontam a direção de mudanças que perscrutamos. Essas mudanças na clínica também são demandadas por diversos setores da sociedade nos espaços híbridos de participação e protagonismo criados no interior do sistema de saúde atual.

\section{Construindo Outras Modalidades para a Escuta: uma arqueologia da organização e das práticas em saúde}

Para fazer a incursão acadêmica pelo tema da reconfiguração da clínica e da pedagogia médica (Ferla, 2002), foi necessário forjar uma tecnologia de pesquisa e sistematização de conhecimentos que acoplasse capacidade de escuta à vontade de vida e ao desejo de descobrir e inventar outros padrões para o exercício da clínica médica, bem como perscrutar possibilidades para a educação de profissionais, gestores e conselheiros de saúde. Para tanto, a construção, no seu sentido usual, de agregar segundo uma nota prévia, não ofereceu o necessário campo de possibilidades.

A "carta do campo", tal qual as cartas náuticas - feitas a partir de referenciais móveis, de superfícies sempre outras, com o limite das ferramentas da ciência, o teto das capacidades artesanais e toda a possibilidade de criação -, foi o recurso metodológico escolhido: entrecruzar a rigidez das linhas de rota (o conhecimento biomédico, as idéias oficiais, o norteamento da clínica hegemônica e algumas metodologias prévias) e a sedução do canto da sereia (saberes outros, idéias inovadoras, zonas de fronteira, suleamentos, associações e outros recursos que não foram aprisionados nas linhas de rota) ${ }^{7}$. Sem, contudo, alimentar a pretensão de aprisionar todas as possibilidades em uma nova linha de rota, mais econômica, científica, legítima, factível e tantos outros adjetivos que, do centro do paradigma sociocultural moderno, dicotomizam a "ciência verdadeira" da mentira e da fronteira. Cartografar possibilidades desse campo, buscar configurações nas dobras das práticas e dos discursos oficiais e engendrar pontos de contato com idéias populares, associando-as a marcas e cicatrizes próprias e, principalmente, ao desejo de experimentar a clínica em saúde, no sentido que motivou a busca pela formação acadêmica em medicina: esse foi o ponto de partida e a bússola que alimentaram e orientaram o trabalho realizado por ocasião da pesquisa que originou a tese de doutorado (Ferla, 2002). 
Para isso, foi necessário escavar o solo das práticas hegemônicas, numa arqueologia da medicina moderna, mas também da saúde pública tal como vem sendo exercida, em particular da gestão dos sistemas e serviços de saúde. Assim, foi reconstituída a trajetória técnica, política e social do surgimento da medicina moderna, sua articulação com a ciência moderna, com o hospital médico e com uma pedagogia médica, mas também com o Estado, irradiando ações médicas de disciplinamento e de ordenamento sobre os indivíduos e grupos sociais. São ações que se constituem e se insinuam sobre o corpo individual e sobre o corpo social, ao mesmo tempo. Subordinam, por meio de uma racionalidade cognitivo-instrumental hipertrofiada, o social e o político ao técnico-biológico; inserem, na política pública de atenção à saúde, sua visão metodológica tecnificadora e hegemonizada na dimensão biológica.

Essa associação entre a medicina e o Estado - que teve seu surgimento identificado por Michel Foucault (1980) no século XVIII, por meio da medicina estatal alemã (ou "polícia médica alemã"), da medicina urbana francesa e da medicina da força de trabalho inglesa - aconteceu no momento de emergência da necessidade de disciplinar e ordenar os fluxos e a própria vida em sociedade, por decorrência das guerras, das grandes epidemias e do desenvolvimento tecnológico e industrial.

Por outro lado, a medicina nessa época já dominava a clínica: não somente o conhecimento da sucessão dos fenômenos biológicos e fisiológicos visíveis, mas também o discurso que os correlaciona com os fenômenos da vida e a técnica que permite intervir para dominar as disfunções, tecnologias que são atualizadas na experiência clínica, que assujeita aqueles colocados sob seus domínios (médicos e pacientes). Nessa época, a medicina também se insinua sobre o hospital, onde ordem disciplinar e intervenção médica sobre o meio se associam, num ciclo fechado que perpetua a racionalidade e o poder médicos, compondo o chamado "modelo biomédico". Subordina-se, assim, a dimensão social e humana da vida a uma tecnologia biopolítica de gestão da vida (biopoder), chamada de medicalização, compatível e afirmada na própria matriz da ciência moderna, que se fortalece nesse mesmo período da história.

Também por volta dos séculos XVII e XVIII, outro autor que emprestou à cartografia várias ferramentas de trabalho, Boaventura Santos (Santos, 1997) identificou a articulação dos aspectos políticos, sociais e culturais da modernidade. Para esse autor, o projeto sociocultural da modernidade constituiu a promessa de equilíbrio entre forças de regulação (articuladas pelos princípios 
do Estado, do mercado e da comunidade) e de emancipação, configuradas pelas racionalidades cognitivo-instrumental (da ciência e da técnica), moralprática (da ética e do direito) e estético-expressiva (das artes e da literatura). Na hipertrofia da primeira racionalidade sobre as demais, rompendo o equilíbrio sobre o qual se constituía a promessa de uma pressão emancipadora à modernidade, está uma das origens da crise do projeto moderno. Segundo Boaventura Santos (Santos, 1997, p. 236), "à medida que a trajetória da modernidade se identificou com a trajetória do capitalismo, o pilar da regulação veio a fortalecer-se à custa do pilar da emancipação". Buscar zonas de fronteira, de silenciamento, tensões e rupturas, fragmentos pré-paradigmáticos é a sugestão do autor para identificar o que emergirá dessa crise e para fomentar essa emergência.

Nesse mesmo contexto histórico, uma ordem pedagógica racionalizadora, assentada na tríade composta por uma dimensão antropológica, uma dimensão metodológica e uma dimensão teleológica, transversalizou os diversos campos de práticas sociais, inclusive a produção de conhecimentos, para constituir um "modo verdadeiro" de ser e estar no mundo, universalizando um conjunto de valores capaz de produzir, na ordem ocidental moderna, as possibilidades consideradas legítimas de viver a vida (Dorneles, 1996). Essa ordem pedagógica moderna, derivada da cultura européia que lhe deu origem (seu norte), estabelece uma objetivação racionalizada para o ser/existir, a razão científica como o modo de "iluminar" a compreensão do universo e constituir/ordenar os modos de ser/existir e a idéia de progresso (traduzida no avanço ordenado em direção a maiores gradientes de estabilidade). Em oposição a essas definições e no lugar do ilegítimo, coloca as diversas outras possibilidades de constituir tais dimensões (os suleamentos ${ }^{8}$ ), muitas das quais próprias das alteridades expressas nas mestiçagens latino-americanas, dos seus modos múltiplos de produzir e combinar conhecimentos e sua capacidade de ir fazendo caminhos ao caminhar.

Essa ordem moderna, que garantiu à configuração emergente da medicina ocidental no final do século XVIII espaço privilegiado de trânsito pela sociedade, tem sido tensionada. O paradigma sociocultural moderno, no qual essa ordem está assentada, vem demonstrando uma sucessão de crises que apontam para o esgotamento de sua viabilidade (Santos, 1997). No contexto dessa crise, abrem-se novas possibilidades de emancipação social, de reinvenção da democracia, de emergência de práticas e racionalidades próprias de grupos sociais, comunidades e sociedades que foram colonizadas pela ordem moderna. Essas possibilidades de 
ser, existir e fazer, que foram se engendrando nos lugares periféricos, afastados das "luzes" da razão moderna, são fortalecidas com a crise que atualmente se apresenta.

No sistema de saúde brasileiro, uma forte expressão dessa crise foi apropriada no processo de reforma sanitária. Principalmente desde a década de 70, forças dos movimentos popular, sindical, acadêmico e de profissionais de saúde vêm incluindo na agenda política nacional questões inovadoras em relação ao conhecimento e às práticas em saúde, tanto no que diz respeito aos aspectos metodológicos da atenção à saúde e da organização dos serviços, como nos aspectos teleológicos e antropológicos. Ação interdisciplinar, aumento da qualidade de vida, regulação pública sobre as práticas de saúde, participação horizontal e propositiva do usuário (no momento do atendimento) e da população (na gestão do sistema de saúde) são idéias que não emergem naturalmente nas lógicas estabelecidas na modernidade, tanto para organizar as estruturas do Estado na área da saúde quanto para reproduzir ações médicas. Apesar disso, essas idéias estão gravadas no texto constitucional e estão em curso no país, chocando-se com a atenção medicalizadora, derivada do modelo biomédico.

Esse tensionamento tem sido verificado particularmente no espaço dos Conselhos de Saúde, um sistema nacional de órgãos colegiados existentes em todas as esferas de governo (municípios, estados e União), composto por representantes dos usuários, do governo, dos trabalhadores da área e dos prestadores de serviço. Da mesma forma, nas Conferências de Saúde, uma rede de eventos regulares discute e delibera sobre diretrizes e a configuração das políticas de saúde.

Nesse contexto de crises, tensões, transformações e tentativas de legitimação dos modos (normal x inovadores) de organizar e propor a atuação em saúde e os modos de vida, na pesquisa anterior (Ferla, 2002) dois territórios foram explorados em busca de idéias para reconfigurar a clínica médica: o território indicado pelas publicações médicas das duas principais entidades representativas desses profissionais (Associação Médica Brasileira - AMB e Conselho Federal de Medicina - CFM) e o território expresso nas formulações do controle social em saúde, particularmente o Conselho Estadual de Saúde do Rio Grande do Sul (CES/RS). Os achados daquela produção relevantes para a reflexão feita neste artigo serão associados a evidências capturadas durante a realização da XII Conferência Nacional de Saúde. 


\section{Identificando Evidências de Inovação na Clínica, na Gestão e na Participação da População}

No percurso pelos territórios que constituíram o campo de busca dessas idéias no trabalho anterior, foram constatados, enfática e reiteradamente, descritores da crise da medicina, bem como de sua racionalidade hegemônica.

Também foram encontradas idéias potentes para constituir possibilidades que denominamos clínica nômade, e também elementos para configurar tecnologias para sua produção, ou seja, o que passamos a caracterizar como uma pedagogia médica mestiça. Das inovações cartografadas, registramos as idéias que julgamos mais potentes em torno desses dois conceitos, que abrem novas fronteiras para o território da medicina: uma pedagogia que permite chegar à medicina pela sua fronteira sul e uma clínica suleadora. Essas inovações demandam mudanças na gestão dos processos no interior dos quais elas se realizam.

\section{Pedagogia Médica Mestiça}

No contexto da crise da medicina moderna, não foi somente a clínica que sofreu conseqüências: sua pedagogia medicalizadora também foi afetada. A visão antropológica da medicina (constituída sobre um plano de identidades representadas na dicotomia médico-paciente), a visão metodológica (fundamentada no conhecimento anátomo-patológico) e a visão teleológica (orientada pelo progresso tecnológico e pelo desafio do domínio sobre a doença e a morte) sofreram fortes tensões, identificadas em produções médicas e também nos espaços do controle social. Os tensionamentos, que vêm atingindo essas três dimensões conceituais, criam campos de possibilidades que, não somente se mostraram inovadoras, como também permitem a expressão de modos fronteiriços e movediços muito particulares, tanto para a pedagogia médica quanto para a clínica.

A pedagogia médica emergente não é, na realidade, uma combinação precisa de visões uniformes de cada um dos seus três componentes, de forma equivalente à pedagogia da biomedicina. Trata-se, na realidade, muito mais do potencial de ruptura com aquela configuração vigente do que sua substituição por outra combinação equivalente. Entretanto, para além da heterogeneidade e multiplicidade de sentidos, há um recorte mais expressivo que é comum às três dimensões dessa pedagogia médica emergente: uma mestiçagem que lhe é 
constitutiva. Ou seja, em qualquer das suas dimensões, o que há de comum e mais potente entre as idéias cartografadas é a emergência de possibilidades que eram consideradas "impuras" pela pedagogia e pela medicina. Emergência para um espaço que dá visibilidade ao protagonismo dinâmico, instável, dessas idéias e dos atores que as formulam. Não se trata de substituir o que se constituiu como dominante pelo que, mesmo que diverso e heterogêneo, foi colonizado e silenciado. Trata-se de uma mestiçagem mesmo: um amplo espectro de combinações, envolvendo idéias dominantes no paradigma atual e idéias inovadoras, que têm em comum entre si apenas o fato de constituir-se num potente espectro de possibilidades em movimento. Ou, conforme define Serres (1993, p. 106), são os lugares que estão entre uma margem e outra; é o espaço pelo qual se transita: é a larga estrada que está entre duas cristas: "das instituições da ciência e das colinas do silêncio".

Essa mestiçagem captada, aliás, tem uma característica própria dos territórios localizados ao sul. No que se refere aos sistemas de práticas e racionalidades médicas, o continente latino-americano, mestiço por condição de existência, é pródigo em apresentar tais mestiçagens.

A dimensão antropológica é um bom exemplo das mestiçagens dessa pedagogia emergente. Registros de inovação foram coletados não somente em relação ao "outro" da clínica médica, mas também daqueles que a exercem. Por decorrência da variedade de aspectos identificados, que põem em questão a uniformização identitária do humano e rompe seus limites visíveis, associados a um compromisso ético-estético-político, que é próprio da clínica (da clínica que se quer clínica), surgem idéias que a desterritorializam também, tornandoa uma clínica nômade e ancorando-a não mais apenas em uma racionalidade cognitivo-instrumental própria, conforme o fez a "medicina normal", mas em um compromisso político com a afirmação da vida.

A construção epistemológica moderna da doença, sua absorção num campo de tecnologias discursivas (a experiência clínica) e o assujeitamento dos atores da cena do cuidado em saúde (médicos e "pacientes") mostraram ser os principais aspectos da crise da medicina. Essa constatação foi recorrente no território da medicina e no território do Conselho, embora mais intensa em idéias e práticas no segundo território e nas fronteiras do primeiro, na expressão de outras racionalidades e práticas médicas não dominantes, mas também nas disputas corporativas e nas discussões mais desestabilizadoras, como em relação à morte. As produções textuais que circularam pelas publicações médicas, pela 
imprensa comercial e por algumas discussões no território do controle social, sobre a morte encefálica, durante o período de vigência da legislação nacional que instituiu o princípio da doação presumida, sobre a medicina baseada em evidência, protocolos clínicos e a bioética mostraram significativa heterogeneidade e uma evidente ruptura com o disciplinamento corporativo do exercício profissional (Ferla, 2002). Movimento sem dúvida similar à discussão do conceito de "ato médico" durante a XII Conferência Nacional de Saúde, que, apesar da veemente defesa das entidades médicas, foi rejeitado como diretriz no relatório final.

As idéias inovadoras captadas mostram uma heterogeneidade móvel, apontam para uma mestiçagem na visão do humano, objetualizado pela biomedicina: sejam homens e mulheres que buscam cuidados ("pacientes", na racionalidade biomédica), mas também homens e mulheres médicos, estudantes, trabalhadores em saúde. Não se trata, em nenhum caso, de uma unidade fixa, de um conceito puro, de um único e exclusivo papel a desempenhar.

Em relação ao "paciente", há três aspectos importantes que apontam para uma fratura nessa abstração medicalizada e totalizante. Um primeiro aponta uma diversidade bem evidente desse "ser" e seus modos de estar no mundo. As idéias capturadas mostram grandes desafios para a clínica: o desafio de utilizar-se de mecanismos que permitam enxergar/escutar a diversidade que se expressa em cada situação de atendimento (em substituição à abstração na doença universalizada), o desafio de reconfigurar-se a partir dessa diversidade para propor ações que se ajustem à situação concreta e única do momento do contato do profissional com o usuário encarnado (em substituição às identidades universais do "paciente" e do "médico", bem como das tecnologias terapêuticas padronizadas que operam desde a experiência clínica moderna que, tal qual um software, emite operações fixas ante estímulos predefinidos) e o desafio de combinar-se lateralmente com outros conhecimentos e práticas, bem como nas possibilidades de atenção oferecidas por outros serviços do sistema de saúde, para oferecer os melhores cuidados ao usuário (em substituição à lógica da autonomia das práticas de cada um dos profissionais, em detrimento da qualidade do cuidado prestado ao usuário).

Se o reconhecimento da existência de um ser mestiço impõe a reconfiguração local da clínica (em cada situação concreta de atendimento), com o uso de novos dispositivos para seu exercício (escuta à vida), há também uma segunda decorrência dessa quebra. Um conjunto de idéias inovadoras, 
agrupadas em torno do princípio bioético da autonomia, agrega mais um plano de complexidade no conceito do "outro" da clínica e no seu próprio exercício. As ações de cuidado precisam assegurar menos a sedação da doença e mais padrões progressivos de autonomia para o usuário. $\mathrm{O}$ resultado primeiro do cuidado é aumentar a qualidade do andar a vida de cada um, o que torna a clínica, definitivamente, não mais a arte de aplicar a ciência do cuidado, mas a ciência de aplicar a arte do cuidado ${ }^{9}$.

Um terceiro aspecto na concepção do "outro", que também está no plano das idéias inovadoras é, justamente, a concomitância, nesses planos de inovação, do "paciente" da racionalidade biomédica. A visão absoluta dessa abstração é anunciada como francamente inadequada no território do Conselho, insuficiente nas racionalidades e práticas não dominantes e incompleta na própria clínica biomédica (espera-se que o "paciente" não somente busque o atendimento, como também que se deixe medicar e siga as recomendações; tenha, portanto, um protagonismo relativo orientado pelo discurso médico).

Entretanto, não há uma negação radical da condição de submeter-se aos cuidados profissionais no momento do adoecimento. Em nenhum dos territórios se evidenciou qualquer idéia de negação completa dos cuidados médicos, mesmo que estes objetualizem duplamente o sujeito num "corpo-deórgãos" e na doença durante a ação assistencial. Na situação limítrofe, quando essa objetualização reduz drasticamente a possibilidade de protagonismo, conforme foi registrado no próprio território da medicina, sabe-se que o doente que busca a tecnologia biomédica (à qual se submete pacientemente no momento da assistência direta, se assim lhe for imposto). Concomitantemente, poderá buscar outras práticas e o cuidado em outras racionalidades ou, mesmo, não implementará as recomendações da forma como foram prescritas. Ou seja, mesmo do ponto de vista da medicina "normal", o "paciente" não é um conceito perfeito.

Para além desse limite da abstração médica, o humano que emerge de algumas práticas de saúde (na periferia do território da medicina) e também na aproximação feita pela sua fronteira ao sul (inclusive pelo território do Conselho), é um ser encarnado, com características singulares e formas próprias de andar a vida. Quando está adoecido, sofre concretamente. Sua dor nãoé uma abstrata combinação de sinais e sintomas, produzida por fenômenos eletroquímicos anormais instalados em algum lugar preciso no conjunto dos seus órgãos. Sua morte não é apenas o silêncio do tronco encefálico, e mesmo 
os fragmentos de seu corpo, por ocasião da decretação de sua "morte encefálica", não são apenas insumos ou peças a serem deslocadas para outros organismos (e, quando o transplante é feito, o corpo que o recebe torna-se ainda mais mestiço). A vida mesma não é apenas um silêncio passivo e a saúde não é um estado de "equilíbrio" no funcionamento dos órgãos. Não há uma máquina humana: há um corpo que sofre, que se transmuta constantemente, recheado de devires e prenhe de possibilidades, que demanda cuidado solidário e escuta sensível.

Embora "paciente" diante de um profissional que assim o procura constituir, o ser que expressa necessidade de cuidado leva consigo, na busca de atenção à saúde, suas inteirezas (como nos dizia Paulo Freire) e é dessa forma que precisa ser compreendido. A redução dessas múltiplas inteirezas, que são próprias do humano, à abstração universalizante do "paciente", constituído por um conjunto de órgãos e portador de um conjunto de sinais e sintomas enunciáveis (o diagnóstico) como uma doença (disfunção de órgãos, desordenamento de fenômenos físico-químicos), a partir de uma experiência clínica universal, para torná-lo objeto de uma solução terapêutica ótima; essa redução tem-se mostrado reconhecidamente menos eficaz (para atuar sobre a saúde) e menos legítima (para circular pelos serviços de saúde). Não parece ser totalmente alheio a essa constatação o movimento reativo que se verificou na XII Conferência Nacional de Saúde à normatização legal do "ato médico".

Esse corpo pulsátil e concreto é composto por duas “superfícies". Uma superfície visível registra marcas da história, da sua localização nos espaços e nos tempos sociais, sua condição de gênero, as cicatrizes dos diversos processos de disciplinamento (no sistema educacional, no sistema de saúde, no sistema judiciário etc.). Essa superfície está marcada pelos processos de subjetivação social, que buscam aprisioná-la numa identidade fixa. Mas há também uma superfície invisível, incrustada nas dobras do corpo, com forças em movimento, afetos, devires, alteridades. Esta precisa ser escutada e enxergada como vida que pode vingar (Nietzsche, 2002) e singular. Precisa, portanto, ser mobilizada no cuidado de saúde.

Se a biomedicina conseguiu criar a possibilidade de forjar uma saúde padronizada e constituir, em consonância com as demais instituições da sociedade, uma identidade fixa sobre a superfície visível (mesmo daquela tornada visível pelo olhar do médico no interior desvelado do corpo), nessa outra superfície, invisível e composta nas dobras do corpo, há mil saúdes, como nos 
disse Rotelli (Rotelli \& Leonardis, 1990). Nessa superfície está a grande saúde, da qual nos falava Nietzsche (2002). É abissal a diferença do ser aprisionado pela identidade que lhe é constituída, no espaço social, e também no espaço da relação com os serviços de saúde, e do ser pulsátil e móvel, de existência concreta e que, em momentos diversos da vida, demanda cuidados de saúde aos médicos. O momento atual da configuração do sistema de saúde penhora a essas idéias uma potência maior do que aquela do encontro individual de um usuário com um profissional, num espaço reservado nos serviços de saúde. Elas podem, por decorrência das disposições legais, circular pelo próprio sistema de saúde e contaminar o seu modo de funcionamento: é do "paciente" do discurso médico a principal participação nas estruturas híbridas que deliberam sobre prioridades, uso dos recursos, parâmetros de qualidade para o sistema como um todo e sobre as práticas específicas no seu interior.

$\mathrm{O}$ adoecimento também não é um fenômeno individual. O sofrimento concreto e as consequiências reais do adoecimento relacionam-se com o grupo social, com a família, com a comunidade. Não há uma identidade isolada, uma célula errante, por ocasião do adoecimento. E essa dimensão coletiva do ser múltiplo e mestiço também demanda cuidados e a escuta sensível dos serviços, cuidados não centrados no olhar vigilante e disciplinador da tecnologia (que também é social) da biomedicina.

Se há mil saúdes inscritas no campo de possibilidades do humano (individual e coletivo), elas só tomam vigência se houver protagonismo, se elas forem suscitadas a emergir e se houver disposição (abertura/exposição). O protagonismo torna possível a emergência de uma infinidade de "outros". $\mathrm{O}$ indivíduo, com seu organismo e sua identidade forjados pela modernidade, não faz sentido nessa visão antropológica mestiça que aparece como inovação.

Essa mestiçagem, entretanto, não é somente relativa ao "outro" da clínica. Também o é para o "sujeito" da clínica biomédica. O médico precisa ter capacidade de escuta, de escuta à vida, de tornar-se outro no contato com as pessoas adoecidas, com seu sofrimento. Precisa reconstruir seu próprio saber e não apenas aplicá-lo automaticamente. Essa idéia de protagonismo e de movimento ficou visível na tensão que produziu a medicina baseada em evidências, bem como na resistência que os demais dispositivos disciplinares que as entidades médicas fizeram circular no período analisado na tese de doutorado (Ferla, 2002). Na política institucional das entidades médicas, essa tensão foi sedada por tais dispositivos, que não foram suficientes para anulá-la 
completamente no espaço das práticas dos profissionais. Os profissionais precisam ter/desenvolver a capacidade de reconstruir seus conhecimentos no contato com os outros (os usuários), mas também com seus sentimentos/afetos (contato com seus devires).

Mas não basta que o médico tenha capacidade de escutar o cidadão que procura seus cuidados, tampouco que seja capaz de dar mobilidade ao seu conhecimento, de torná-lo suficiente para o complexo conjunto de elementos que produzem e configuram o sofrimento da pessoa adoecida. É preciso que ele saiba combinar os conhecimentos do seu núcleo específico (sua especialidade) com outros conhecimentos: os conhecimentos mais gerais da sua "especialidaderaiz", do campo de conhecimentos e habilidades específicos da medicina, da área da saúde e do funcionamento do sistema de saúde, dos saberes próprios daqueles que procuram seus cuidados, dos conhecimentos "dispersos" pelo seu entorno e que tornam complexo o diagnóstico e o prognóstico das doenças; é preciso que ele saiba produzir conhecimentos próprios no momento e no espaço em que exerce sua clínica. Essas idéias, ao mesmo tempo em que descrevem uma necessidade de protagonismo que fratura o "sujeito" médico constituído pela medicina moderna ("portador" de uma experiência clínica "pura" que configura suas ações), também anunciam, desde o território da medicina, um novo "modo" de exercício da clínica, com uma mestiçagem de conhecimentos, incluindo conhecimentos e habilidades "impuros" para sua prática (inclusive de fora do campo da medicina e do núcleo das especialidades). Ora, dessa forma, mestiça também é a metodologia emergente para o exercício da clínica, mesmo quando é proposta no território da medicina, principalmente nas suas fronteiras.

Nesse aspecto há uma diferença importante no conjunto de idéias inovadoras identificadas e que são relativas aos aspectos metodológicos do exercício da clínica: algumas delas, no território da medicina, estiveram associadas claramente à idéia de ampliação do espaço de domínio corporativo. A necessidade de ampliar e tornar mais heterogêneo o conjunto de conhecimentos e habilidades responderia, nessa perspectiva, à ampliação das possibilidades das "novas ambições da medicina"10. Mas, mesmo nas idéias inovadoras que circularam por esse território, a maior frequiência delas dá conta da necessidade de superar os limites instituídos pela racionalidade médica hegemônica. Essa é uma necessidade intrínseca à clínica contemporânea, já que um dos elementos reconhecidos de sua crise é um déficit de conhecimentos e, para o campo argumentativo representado por essas idéias, não basta apenas captar as 
"melhores evidências científicas": não é exatamente a diversidade de práticas e de conhecimentos que subsidiam a clínica o problema que está no centro do déficit verificado.

Tecendo apenas as idéias desses dois campos argumentativos localizados no território da medicina, teríamos desdobramentos distintos na visão antropológica relativa ao profissional que a exerce: numa delas teríamos um "sujeito" médico fortalecido, ventríloquo dos discursos e das tecnologias forjadas corporativamente com os "novos" conhecimentos, que assume um leque de conhecimentos com intuito menos de ampliar sua intervenção clínica e mais para fortalecer sua intervenção sobre o sistema de saúde que o circunda. Noutra perspectiva, mais fortalecedora da condição de protagonismo, está suscitada a configuração de uma clínica capaz de liberar-se do script predeterminado de discursos e práticas e combinar conhecimentos mestiços e a situação concreta de cada encontro para o exercício da clínica. A segunda perspectiva constituiria, seguramente, a possibilidade de uma clínica nômade.

\section{Clínica Nômade}

Nesse contexto, algumas idéias mostraram a necessidade de combinar, pela interação interdisciplinar e pelo contato sensível com os saberes dos usuários, as melhores composições de conhecimentos: é preciso a capacidade de combinação lateral de conhecimentos e práticas; há uma horizontalidade entre os diversos planos de saberes e de fazeres que estão associados no momento do exercício da clínica e é uma combinação de conhecimentos e práticas o mais próximo possível desse plano de horizontalidade (horizontalidade entre os conhecimentos das várias profissões, mas também o protagonismo informado do usuário e de seus familiares) que potencializa a clínica. Ou seja, o traço mais forte da mestiçagem relativa à visão metodológica diz respeito a uma certa sensibilidade/abertura ao outro (profissional e usuário). Ou, como se disse anteriormente, de um compromisso estético, capaz de expressar-se em novos arranjos para a clínica no contato com as diferenças com que se depara a cada atendimento.

Entretanto, no território do conselho, o médico - como os demais trabalhadores de saúde - tem sua condição humana reconhecida com mais ênfase: não há necessidade de que seja infalível ou que tenha um grande domínio horizontal (complexidade de conhecimentos e práticas) de uma vasta quantidade de núcleos de conhecimento (sofisticação de conhecimentos e 
práticas). Mais do que a autonomia/auto-suficiência do médico, no território do conselho a idéia que tem mais vigência, que descreve o acesso resolutivo aos serviços, é a capacidade de escuta dos profissionais e de associar-se horizontalmente com as habilidades específicas outros trabalhadores e com o funcionamento de outros serviços.

Emerge assim, mais um plano de idéias, relativo ao modo de exercício da clínica e que diz respeito à expectativa do domínio individual do máximo de sofisticação de conhecimentos (decorrente da expectativa de exercício autônomo), mais freqüente no território da medicina, e à expectativa de um domínio horizontal e uma sensibilidade individual, capazes de compor uma complexidade de conhecimentos suficiente para fortalecer a resolutividade dos cuidados. Entrecruzam-se, novamente, em ambos os territórios, as visões antropológicas e metodológicas. Outra dimensão, a teleológica, também está imbricada nessa íntima associação entre essas dimensões. Antes de tecer mais esse plano de idéias, é importante localizar as duas primeiras dimensões no processo de formação dos profissionais.

No território da medicina, o "ser" estudante e a aprendizagem foram abordados de forma discreta e superficial. Avaliou-se a necessidade de reconhecer perfil e expectativas do estudante para orientar o processo de formação, bem como de se prover, no processo de formação, espaços de vivência do estudante na rede de serviços. Mais do que volume de conhecimentos técnicos adquiridos por contato, diz-se que é preciso desenvolver tecnologias para o contato com o diverso: é preciso deixar-se mestiçar para o aprendizado da clínica. O aprendizado e o aprendiz, por extensão, precisam desenvolver protagonismo, caracterizado principalmente pela abertura à experiência vivencial do cotidiano desordenado dos serviços.

Essas idéias, relativas ao aprendiz e ao aprendizado, têm mais vigência no espaço do conselho: a experiência vivencial e o protagonismo do estudante devem constituir sua clínica, e projetos e atividades são propostos para isso. Espera-se que desenvolvam o compromisso ético e político com o sistema de saúde (não somente na internalidade dos serviços assistenciais, mas nos demais ambientes por onde circulam instrumentos, fluxos, usuários, trabalhadores, gerentes de serviços e gestores, particularmente nos espaços onde se exerce o controle social) e que, associando-o ao conhecimento biomédico e à sensibilidade aos demais conhecimentos e racionalidades do campo da saúde (das demais profissões, das demais práticas, mas também do conhecimento pragmático dos 
usuários), exerçam sua clínica. A clínica, assim exercida, com uma combinação de sofisticação e de complexidade de conhecimentos e práticas, orientadas pelo compromisso ético, estético e político, nos conduzem a outro dos conceitos que foram tecidos até aqui: a clínica nômade.

O compromisso político proposto e demandado à clínica é relativo à defesa da vida, da saúde e do sistema de saúde tal qual está desenhado constitucionalmente. Nesse sistema, um conceito ampliado de saúde, uma expectativa diferenciada acerca das práticas de cuidado e uma combinação complexa de conhecimentos estão associados ao conceito de integralidade com eqüidade, largamente reiterado durante a XII Conferência Nacional de Saúde. $\mathrm{E}$, dessa combinação inovadora de conceitos, surge a necessidade de escuta à vida, como dispositivo para a produção de saúde, mas também, por decorrência, a luta contra o que atenua e seda qualquer das mil saúdes possíveis a cada momento. Assim, mais do que o progresso tecnológico e o fortalecimento corporativo, é preciso ir fundo no que produz adoecimentos, no que serializa e disciplina os sonhos, no que bloqueia a emergência de projetos mais saudáveis e democráticos de sociedade e no que aprisiona o humano a identidades fixas e definidas aprioristicamente ${ }^{11}$. O compromisso político da clínica, nômade porque clínica e porque defensora da vida, desdobra-se, dessa forma, no dever de ofício de tornar presentes (de fazer vingar) possibilidades mais saudáveis de futuro, heterogêneas, mestiças e sensíveis, assim como a saúde requer.

Essas idéias capturadas na cartografia, que não são dominantes no território da medicina e tampouco têm vigência plena no sistema de saúde atual, vêm mostrando potência para encadear mudanças. Mostram, na medida da sua viabilidade, que a inovação, mais do que um recurso conceitual e/ou metodológico, pode representar um plano de possibilidades em emergência da atual crise paradigmática da modernidade.

Na perspectiva que apontam as idéias inovadoras capturadas no território da medicina e no território do conselho, há nascentes de inovação que transbordam para um território mais ampliado, da saúde, de uma Grande Saúde. Como nos disse Nietzsche (1999, p. 206-7):

"Nós, os novos, os sem-nome, os difíceis de entender, nós, os nascidos cedo de um futuro ainda não demonstrado - nós precisamos, para um novo fim, também de um novo meio, ou seja, de uma nova saúde, de uma saúde mais forte, mais engenhosa, mais tenaz, mais temerária, mais alegre, do que todas as saúdes que houve até agora (...). Da Grande Saúde - de uma saúde tal, que 
não somente se tem, mas que também constantemente se conquista ainda, e se tem de conquistar, porque sempre se abre mão dela outra vez, e se tem de abrir mão!”.

Dito de outro modo, o desafio colocado aos profissionais, usuários e gestores da saúde é descobrir constantemente novas saúdes, para a luta valer a pena. Dessa perspectiva, muito provavelmente, se houver evidência de crise da capacidade produtiva e criadora dos espaços de participação da população no sistema de saúde, ela deverá ser buscada junto à configuração que assumiu há pouco mais de 15 anos essa diretriz constitucional: o controle sobre os recursos. A produção da XII Conferência Nacional de Saúde, que, mesmo diante de uma situação de grandes dificuldades, principalmente financeiras e operacionais, do sistema de saúde, reiterou de forma enfática os princípios e diretrizes do SUS, parece indicar que está havendo, mas do que uma crise de criatividade dos setores da sociedade que participam do sistema de saúde, uma crise de capacidade interpretativa dos setores voltados à análise dessa participação. Sobre a capacidade da participação da população nos espaços institucionais do sistema de saúde para engendrar novos planos à estética da clínica e da gestão em saúde, muitas evidências apontam um sentido propositivo e afirmativo de novos modos de exercê-las.

\section{Referências}

CAPISTRANO FILHO, D. Da saúde e das cidades. São Paulo: Hucitec, 1995.

CECCIM, R.B. Criança hospitalizada: a atenção integral como escuta à vida. Porto Alegre: UFRGS, 1997.

CECCIM, R.B. Políticas da inteligência: educação, tempo de aprender e dessegregação da doença mental. 1998. Tese (Doutorado em Psicologia Clínica) - Programa de Estudos Pós-graduados em Psicologia Clínica. Pontifícia Universidade Católica de São Paulo, São Paulo, 1998.

CÔRTES, S. M. V. Conselhos Municipais de Saúde: a possibilidade dos usuários participarem e os determinantes da participação. Ciência \& Saúde Coletiva. Rio de Janeiro, v. 3, n.1, p. 5-17, 1998. 
COWAN, J. $O$ sonho do cartógrafo: meditações de Fra Mauro na corte de Veneza no Século XVI. Rio de Janeiro: Rocco, 1999.

DORNELES, M. A. Lo público y lo popular en el ámbito racionalizador del orden pedagógico moderno. 1996. Tese (Doutorado em Ciências da Educação) - Faculdade de Filosofia e Humanidades, Universidade Católica de Córdoba. Córdoba, Argentina, 1996.

FERLA, A. A. Clínica nômade e pedagogia médica mestiça: cartografia de idéias oficiais e populares em busca de inovações à formação e à clínica médicas. 2002. Tese (Doutorado em Educação) - Universidade Federal do Rio Grande do Sul. Faculdade de Educação. Programa de Pós-graduação em Educação, Porto Alegre, 2002.

FERLA, A. A.; FAGUNDES, S. M. S. (Org.). Tempo de inovações: a experiência da gestão da saúde no Rio Grande do Sul. Porto Alegre: Da Casa, 2002.

FOUCAULT, M. O nascimento da clínica. 1980. . Microfísica do poder. Rio de Janeiro: Graal, 1989.

FREIRE, P. À sombra desta mangueira. São Paulo: Olho D’água, 1995.

GARELLI, F. Controle social. In: BOBBIO, N. et al. (Org.). Dicionário de Política. Brasília: UNB, 1997. v. 1, p. 283-285.

GUATTARI, F. Caosmose: um novo paradigma estético. Rio de Janeiro: Editora 34, 1993.

KUHN, T. S. A estrutura das revoluções científicas. São Paulo: Perspectiva, 2001.

KUNKEL, M. B. Humanização na saúde e cidadania: o caminho para o SUS. In: FERLA, A. A.; FAGUNDES, S. M. S. (Org.). Tempo de inovações: a experiência da gestão da saúde no Rio Grande do Sul. Porto Alegre: Da Casa, 2002. p. 195-202.

NIETZSCHE, F. Fragmentos finais. Brasília: UNB, 2002. Nietzsche: vida e obra. São Paulo: Nova Cultural, 1999 (Coleção Os Pensadores). 
PINHEIRO, R.; MATTOS, R. A. (Org.). Os sentidos da integralidade na atenção e no cuidado à saúde. Rio de Janeiro: UERJ/IMS, 2001.

PRIGOGINE, I.; STENGERS, I. A nova aliança: metamorfose da ciência. Brasília: UNB, 1997.

ROLNIK, S. Pensamento, corpo e devir: uma perspectiva ético-estético-política no trabalho acadêmico. Cadernos de Subjetividade, v. 1, n. 2, p. 241-52, fev. 1993.

ROTELLI, F.; LEONARDIS, O.; MAURI, D. Desinstitucionalização, uma outra via: a reforma psiquiátrica italiana no contexto da Europa Ocidental e dos "países avançados". In: ROTELLI, F. (Org.). Desistitucionalização. São Paulo: Hucitec, 1990. p. 17-59.

SANTOS, B. S. Pela mão de Alice: o social e o político na pós-modernidade. São Paulo: Cortez, 1997.

SERRES, M. Filosofia mestiça: le tiers-instruit. Rio de Janeiro: Nova Fronteira, 1993.

VALLA, V. V. A crise de interpretação é nossa: procurando compreender a fala das classes subalternas. Educação e Realidade. Porto Alegre, v. 21, n. 2, p. 177-190, jul./dez. 1996.

\section{NOTAS}

${ }^{1}$ Médico; doutor em Educação (UFRGS); secretário Substituto da Secretaria da Saúde do Estado do Rio Grande do Sul e representante governamental na Mesa Diretora do Conselho Estadual de Saúde do Rio Grande do Sul, no período de 1999 a 2002; assessor da Direção do Grupo Hospitalar Conceição; pesquisador do Laboratório de Pesquisa de Práticas de Integralidade em Saúde (LAPPIS/ IMS/UERJ) e do Núcleo Interdisciplinar de Pesquisa em Saúde Coletiva (NIPESC/IFCH/UFRGS).

${ }^{2}$ As referências à XII Conferência Nacional de Saúde são de apontamentos do próprio autor e do número especial da Revista Radis: Comunicação em Saúde (n. 18, fevereiro de 2004), também disponível na Internet, em < www.ensp.fiocruz.br/publi/radis >.

${ }^{3}$ A referência à ciência normal, à medicina normal e outras que atribuem tal característica às áreas de conhecimento foi tomada da obra de Tomas Kuhn (2001), na qual o atributo de normalidade se refere à produção feita na perspectiva do paradigma vigente.

${ }^{4}$ Designação corrente, no caso brasileiro, aos espaços institucionais e processos sociais que buscam a implementação da diretriz constitucional de participação da população no sistema de saúde. É um sentido, portanto, muito diferente daquele da filosofia política clássica, que assim designa o "conjunto de meios de intervenção, quer positivos ou negativos, acionados por cada sociedade ou grupo social, 
a fim de induzir os próprios membros a se conformarem às normas que a caracterizam, de impedir e desestimular os comportamentos contrários às mencionadas normas, de restabelecer condições de conformação, também em relação a uma mudança do sistema normativo" (Garelli, 1997).

${ }^{5}$ Como exemplo, em inúmeras situações, durante os trabalhos da XII Conferência Nacional de Saúde, militantes ligados ao movimento indígena e à educação popular registraram como insuficientes e até ilegítimas as práticas oficiais/predominantes nos serviços de saúde. Reivindicaram e agregaram ao relatório popular" e pelo "modo de vida" dos índios do que pela perspectiva das "doenças dos médicos" (registros do autor).

${ }^{6}$ Categorias construídas a partir dos conceitos nietzscheanos de arte trágica e dramática (Nietzsche, 2002).

${ }^{7}$ Metáfora construída a partir da obra Meditações de Fra Mauro (Cowan, 1999, p. 25-9): "Ao longo do tempo tenho aprendido a reconhecer a beleza das linhas de rota e da rosa-dos-ventos. Elas fazem as delícias dos navegadores, pois são as linhas que todo marinheiro percorre em busca dos vários pontos da bússola. (...) O que está além dos limites do mundo às vezes nos atrai como um canto de sereia. (...) Os limites fortemente delineados dos mapas que tenho observado, ao longo dos anos, são indicadores dessa atitude [também] por parte dos navegadores. Eles são completamente seduzidos pela perspectiva de continuar em determinada direção até alcançar o ponto mais distante. Querem descobrir se o último objetivo corresponde às suas idéias de como o mundo realmente é. (...) Meu papel como cartógrafo é equivalente ao descobrimento do mundo. (...) Estou à procura de novas idéias e visões. Não quero afirmar o que já sei. Cada mapa que desenho é feito tanto com as informações que recebi de visitantes à minha cela, quanto com as minhas próprias idéias, inspiradas por seus conhecimentos e, freqüentemente, por seus comentários preciosos e fantásticos. (...) Juntos, cartógrafo e aventureiro discutem sobre distâncias e rotas, sabendo, silenciosamente, que nada mais são do que diversão, pois o que estamos tentando é dar sentido a conhecimentos disparatados".

${ }^{8} \mathrm{O}$ norte é a direção que nos aponta o paradigma moderno como a direção correta: está na posição superior do mapa, é o lugar do progresso e do desenvolvimento, como nos ensina a geografia política. Assim, quando se busca a inovação, parece adequado estranhar essa direção única. Esse é o sentido do uso das expressões sulear/suleador (Ferla, 2002).

${ }^{9}$ Corruptela de um slogan muito utilizado na discussão da medicina baseada em evidências, segundo as produções veiculadas nas publicações médicas durante o período da pesquisa anterior (Ferla, 2002).

${ }^{10}$ São bastante esclarecedoras dessa afirmação as produções sobre a medicina baseada em evidências e sobre os protocolos assistenciais que as entidades médicas veicularam no período em que se desenvolveu a pesquisa anterior (Ferla, 2002).

${ }^{11}$ Idéias tecidas a partir da produção de uma Conselheira de Saúde do Estado do Rio Grande do Sul, de extrema relevância na produção acadêmica do autor. Para o aprofundamento dessas idéias a partir da própria autora, ver Kunkel (2002). 


\section{ABSTRACT}

\section{Popular Participation: Social Control of Resources for Aesthetic Production of Clinical Practice and Health Management}

This article reports on part of the prior mapping (Ferla, 2002) of innovative popular and official ideas for clinical practice and medical education, associating this process with similar evidence collected during the national stage of the $12^{\text {th }}$ Brazilian National Health Conference. Analysis of this empirical material indicates that spaces for people's participation in the health system have produced innovative contributions to clinical practice and health system management. These same contributions help reshape clinical practice and management, intervening extensively in the very meaning of social control as customarily interpreted in the 1988 Constitutional provision concerning popular participation in the health system. This trend, which strengthens the aesthetic production of these concepts, is similarly oriented to a set of processes which, according to various authors, demarcates the concepts that modern science has used to produce knowledge. Thus, what is frequently referred to as a crisis in social control of the health system may actually reflect insufficient interpretative resources for grasping a level of greater power in popular participation and more up-to-date expression.

Key words: Popular participation; clinical practice; health management; roving clinical practice; innovation in health.

Recebido em: 16/04/2004.

Aprovado em: 03/05/2004. 